Zur Anatomie der Bilharzia haematobia (Cobbold). Von

\title{
Gustar Fritsch.
}

Hierzu ein Holzschnitt und Tafel XI und XII.

\section{Vorkommen und Verbreitung.}

Als im Jahre 1883 Hr. Robert Koch Aegypten im Auftrage der Regierung bereiste, um das Wesen der Cholera festzustellen, vergass er inmitten seiner berihmten Untersuchungen doch nicht meiner bescheidenen Bitte, auf die dort auftretenden menschlichen Parasiten, besonders auf die Bilharzia zu achten und mich guitigst in Besitz von Untersuchungsmaterial zu setzen.

Obwohl ich selbst mehrfach in Aegypten war und bei dem letzten Aufenthalt auch Gelegenheit fand mit dem eifrigen Parasitenforscher Sonzino in Verbindung zu treten, so hatten sich die Bexiehungen der Eingeborenen zu den Europüern doch in jenen Jahren so schwierig gestaltet, dass die zu der Untersuchung nothwendige Leicheneröffnung nicht zu erlangen war.

Der Wunsch, die schwer auf dem Lande lastende Geissel der Cholera hinweggenommen zu sehen, liess dann aber die Aegypter begreiflicher Weise alle sonstigen Bedenklichkeiten vergessen, und so hatte mein hochverebrter Freund Koch die Möglichkeit der Wissenschaft auch hierin einen erheblichen Dienst zu leisten. Er constatirte aufs Neue die ausserordentliche Verbreitung: dieses gefährlichen Parasiten, wie sie früber von Bilharz und Griesinger in Aegypten, von Harley, Henderson, Atherstone und Anderen am Cap beobachtet worden war. Fand Griesinger die Distomen in 30 Sectionen $17 \mathrm{mal}$, Sonzino in $54 \mathrm{Sec}-$ tionen $30 \mathrm{mal}$, wurden in Uitenhagen (Capcolonie) von 3 Knaben 2 damit behaftet gefunden, so beobachtete $\mathrm{Hr}$. Koch, dass unter 10 Eingeborenen 9 von dieser Krankheit heimgesucht waren, welche regelmässig erhebliche Störungen in den Organen setzt und nicht 
selten den Tod zur Folge hat. Summirt man die Fälle von Schädigung der menschlichen Gesundheit durch diesen Wurm und stellt die Zahl in Vergleich mit den im gegebenen Fall zwar verderblichen, aber glücklicher Weise doch nur sporadisch auftretenden Erkrankungen an Trichinose, so muss man die Bitharzia als einen schlimmeren Feind der Menschheit erkennen als selbst die so gefürchtete Trichine.

Es kommt hinzu, dass man sich gegen die Einwanderung der letzteren durch einige Vorsicht recht wohl schützen kann, während leider das Eindringen der Distomen in den Menschen noch nicht genïgend aufgeklärt ist, um die richtigen Schutzmittel mit Sicherheit angeben zu können; aber auch wenn wir die Lebensgeschichte vollständig verstehen, wird man sich vielleicht nicht genügend gegen den tückischen Feind zu schützen vermögen. Hr. Küchenmeister hat in seinem schätzenswerthen Werk über die Parasiten des Mensehen (2. Auflage) mit grossem Fleisse alle Angaben über das Vorkommen der Bilharzia zusammengestellt und die Möglichkeiten ihres Eindringens in den Menschen erörtert. Zufälliger Weise hatte ich Gelegenheit, einen grossen Theil ibres Verbreitungsbezirkes, d. h. ausser Aegypten in seinen verschiedenen Provinzen auch Uitenhagen, Pieter-Maritzburg und Port Natal in SudAfrika aus eigener Anschauung kennen zu lernen und Erkundigungen einzuziehen. Nach den Ergebnissen derselben glaube ich doch nunmehr der Ueberzeugung Ausdruck geben zu sollen, dass von allen den gegebenen Möglichkeiten nur eine übrig bleibt, welche ïberall, wo der Wurm sicb zeigt, in gleicher Weise in Wirksamkeit tritt, nämlich der Genuss unreinen Trinkwassers besonders aus stagnirenden Lachen.

Weder ist die Gefahr der Inficirung an Inundationsgebiete gebunden; denn Pieter-Maritzburg wie Uitenhagen liegen auf einer hohen Terrassenlandschaft, noch an den Genuss bestimmter Nahrungsmittel wie Gemuise, Brunnenkresse, Salat, Fische, Schnecken oder gar Austern, da die Erkrankung auch bei Personen erscheint, welche solche Nahrungsmittel principiell verschmähen. Flussfische kommen in Süd-Afrika kaum jemals auf den Tiseh, Nilfische werden in Aegypten nur von der ärmeren Bevölkerung gegessen; Salat und Brunnenkresse sind dem Fellachen unbekannte Genüsse, im Caplande sind diese Genussmittel wenigstens sehr 
selten. Ich kann mich nicht erinnern, ausserhalb der Capstadt, Port Elisabeth und D'Urban (Port Natal) in drei Jahren die genannten Vegetabilien überhaupt gesehen, geschweige denn gegessen zu haben.

Ueberall aber, wo die Bilharzia noch beobachtet wurde, findet sich die Nachlässigkeit in Betreff unreinen Trinkwassers, vielfach hervorgerufen oder wenigstens befördert durch die Schwierigkeit sich reines zu verschaffen. So ist es der Fall in SüdAfrika, wo das Wasser meistens aus aufgedämmten Flussläufen, die vielfach nur während der Regenzeit wirklich fliessen, geschöpft wird, so auch in Aegypten, wo vom Nil gespeiste, langsam fliessende Canäle, stagnirende Becken und Cysternen häiufig das Trinkwasser zu liefern haben.

Die Anschauung, dass die Inficirung durch das Trinkwasser erfolgt, erklïrt auch zum Theil die sehr auffallend stärkere Procentzahl des männlichen Geschlechts unter den Befallenen. Die Frauen der Afrikaner, sowohl im mohammedanischen Norden als im christlichen Siiden sind ihren Lebensgewohnheiten nach viel häuslicher als die Männer; sie kommen daber auch viel seltener in die Verlegenheit ,im Felde“ aus beliebiger Wasserpfütze zu trinken, sondern entnehmen ihr Trinkwasser den dafür getroffenen Einrichtungen des Hauses, wo in Aegypten vielfach mit Alaun geklärtes Nilwasser, in Süd-Afrika filtrirtes getrunken wird, aus dem mit dem Schlamm auch die Distomenbrut niedergerissen werden durfte.

Es wird dadurch ferner begreiflich, dass die mit ihrem Trinkwasser im Vergleich zu den Eingeborenen viel reinlicheren Europäer, welche rohe Vegetabilien, Salat, Kresse u. s. w. aber viel mehr als diese géeniessen, verhältnissmässig selten befallen werden.

Entscheidend für mich war ein verbürgter Fall, zwei gebildete Europäer betreffend, die wegen Telegraphenangelegenheiten im Lande herumreisten und dabei auch unreines Wasser zu trinken genöthigt waren. Sie inficirten sich mit den Würmern in unzweideutiger Weise, verliessen das Land für längere Zeit und erreichten dadurch die spontane Heilung von der Infection; später aber, unter dieselben Verhältnisse zurückgekehrt, erduldeten sie sehr bald wieder eine neue Attacke, so dass sie selbst das unreine Trinkwasser mit vollster Ueberzeugung als die Ursache ihrer Erkrankung anklagen mussten. 
Die Möglichkeit des directen Eindringens der Parasiten durch die Harnröhrenmündung beim Baden möchte ich ebenso wie $\mathrm{Hr}$. Kü chenmeister als sehr unwabrseheinlich bezeichnen.

In welcher Gestalt die zur Einwanderung in den letzten Wirth reife Brut sich befindet, ob sie dabei sich eines Zwischenwirthes, wie z. B. der Wasser-Insecten, bedient oder nicht, darüber kann ich so wenig wie meine Vorgänger etwas Bestimmtes aussagen. Weder Hrn. Koch's Berichte, noch die neuesten Untersuchungen von Hrn. Sonzino geben darüber weiteren Aufschluss. Dagegen setzt mich das erhaltene Material erfreulicher Weise in die Lage über die Anatomie des ebenso merkwürdigen wie wichtigen Wurmes Einiges beitragen zu können; sollte die Untersuchung der mir gleichfalls in Aussicht gestellten befallenen menschlichen Organe zu den aus'gedehnten, verdienstvollen Mittheilungen über diesen Gegenstand von Bilharz, Griesinger, Cobbold und neuerdings von $\mathrm{Kartulis}{ }^{1}$ ) wesentliche Ergänzungen liefern, so werde ich mir erlauben in einem spïteren Aufsatz darauf zuriuckzukommen.

\section{Zoologische Benennung.}

Unter den verschiedenen Namen, welche dem Wurme von den Autoren gegeben wurden, wilhte ich den ilm von Hrn. Cobbold verliehenen; denn gewiss gebührt es Bilbarz, dass sein Name mit einem Thiere verknïpft wurde, um dessen Kenntniss er sich zum Besten der Menschheit in so bervorragender Weise verdient gemacht hatte. Es noch unter seinem alten Namen als Distoma haematobium (v. Siebold) zu führen, scheint mir unzulässig, da es in der Zoologie, soviel ich weiss, ohne Beispiel ist, dass getrennt geschlechtliche Arten und normale Zwitter in derselben Gattung vereinigt werden. Diesing's Bezeichnung des Wurmes als "Gynaekophorus" ist offenbar sehr geschickt gewählt, weil sie das auffallendste Merkmal des Thieres bereits enthält und so dem Zweek jeder Namengebung vorzüglich entspricht; nur die Bilharz' Andenken schuldige Rücksicht bestimmt mich, von Diesing's Namengebung abzugehen. Zur Empfehlung der

1) Ueber das Vorkommen der Eier des Distomum haematobium Bilharz in den Unterleibsorganen. Arch. f. pathol. Anat. u. Phys. von Virchow. Bd. 99, p. 139. 
anderen Synonyma, nämlich: Schistosoma. (Weinland) und Thecosoma (Moquin-Tandon) wiisste ich nichts Besonderes anzufihren.

Das grosse Interesse, welches ein so wichtiger, gefährlicher Parasit des Menschen nothwendiger Weise beanspruchen musste, lässt es als selbstverständlich erscheinen, dass die bedeutendsten Helminthologen sich eingehend mit der Natur des Wurmes beschäftigten, ausser den bereits genannten auch Hr. Le u ckart, dem wir in so bohem Maasse für die Erweiterung unserer Erkenntniss in der Parasitenkunde Dank schuldig sind.

Wenn ich nun die vòn ihm gegebene Darstellung der Anatomie der Bilharzia in einigen Punkten glaube vervollständigen zu können, so bin ich weit davon entfernt, daraus auch nur den leisesten Vorwurf gegen ihn, ebensowenig natiirlich gegen Hrn. Küchenmeister, Cobbold oder Sonzino herleiten za wollen. Diese Autoren haben gewissenhaft dargestellt, was ihr Material ihnen zeigte, und mehr darf man billiger Weise nicht verlangen; wenn ich glaube mebr gesehen zu baben, so berubt dies zunïchst in der besseren Beschaffenheit des verarbeiteten Materiales und dann in den Fortschritten unserer Technik, welche jetzt die durchaus nöthige Herstellungr von vollständigen Schnittserien so wesentlich erleichtert. Ohne solehe unter den Händen za haben würde ich allerdings es nicht wagen, eine bestimmte Darstellung der wegen ibrer gestreckten Anordnung etwas schwierigen Organisation des Wurmes zu geben.

Ich glaube im Sinne der genannten Autoren zu handeln, wenn ich nicht bei jedem einzelnen Punkte der zu beschreibenden anatomischen Verhältnisse die etwaigen Differenzen betone, in denen ich mich mit früheren Angaben befinde, sondern nur da, wo aus den abweichenden Angaben weitere Schlussfolgerungen unmittelbar abzuleiten sind. Die nach dem Präparat mit dem Oberbäuserschen Zeichenapparat entworfenen Figuren werden hoffentlich meine Beschreibung geniigend unterstiutzen, zumal sich dieselbe in der Hauptsacbe eng an dasjenige anschliesst, was wir iiber die Organisation der Trematoden überhaupt wissen.

Die Würmchen erscheinen friscb betrachtet im auffallenden Lichte weisslich, wie auch $\mathrm{Hr}$. Le uckart angiebt, hat man aber hellen Hintergrund, z. B. einen weissen Teller, so markiren sich die mit coagulirtem Blut erfüllten dünnen Würmer, besonders die 
Weibchen, daggegen als schwärzliche Fädehen. Darauf machte mich Hr. Koch aufmerksam, der die Thiere am leichtesten auffand, wenn er das Blut der eröffneten Pfortader auf einem weissen Teller auffing.

Das von mir benutzte Material war meinem Wunsche gemüss mit kräftigem Alkohol behandelt und zeigte sich aus diesem Grunde nicht unerheblich geschrumpft, aber dafür waren auch anderseits die bistologischen Elemente recht wohl conservirt und kenntlich geblieben. Die Schrumpfung afficirte zumal das zarter gebaute weibliche Geschlecht und wurden dadurch die Umrisse der Körperquerschnitte etwas unregelmässig. Gleichwohl hielt ich mich nicht für berechtigt, dieselben in den Zeichnungen meiner Ueberzeugung gemäss zu berichtigen, sondern gebe die corrigirten Umrisse lieber gesondert als schematisirt (vergl. die dem Text eingefügten Holzschnitte), um die Vergleichung mit anderen, verwandten Formen zu erleichtern.

\section{Die copulirten Individuen.}

Wenn oben gesagt ist, dass Diesing's Bezeichnung des Wurmes als Gynaekophonus das wichtigste Merkmal des Thieres enthält, so bezieht sich diese Angabe auf das höchst merkwïrdige Verbältniss der beiden Geschlechter zu einander, auf welches ich, bekannt wie es ist, gleich hier nochmals hinweisen möchte, da die Besonderheiten der bisher noch ungenügend erkannten Organisation sich wesentlich an diese Eigenthümlichkeit der geschlechtlichen Beziehungen anlehnen.

Bei der Bilharzia ist die fromme Mythe von der aus Adam's Leibe herausgenommenen Eva Thatsache geworden. Obwohl alle verwandten Arten zwittrig angelegt sind, ist gerade bei dieser einen Form der weibliche Theil des Organismus aus dem männlichen gleichsam herausgelöst und zum selbständigen Individuum geworden; dasselbe bleibt aber in seinen übrigen Organen ansser dem Geschlechtsapparat von einer sonderbaren Dürftigkeit und verleugnet im Habitus die Trematodengestalt fast gänzlich, während das Männchen noch an Stelle der bei anderen Trematoden von den weiblichen Organen eingenommenen Körperregionen eine längs der Bauchseite verlaufende Lücke, den Canalis gynaekophorus der Autoren, aufweist. 
Der durch die Aussonderung des Weibehens im Vergleich zu den Verwandten defekt gewordene Körper strebt gewissermassen danach, sich wieder zu completiren, indem das Weibchen sich an der ihm gebührenden Stelle dem Männchen für ganze Lebensperioden einlagert, das Männchen aber die Ränder seines platten Leibes wie einen Mantel um das Weibchen herumschlägt und so eine zwittrige Thierform mit zwei Köpfen und zwei Schwanzenden vortäuscht.

Diese Vereinigung der beiden Geschlechter geschieht bei vollständiger Reife behufs der Copulation und dauert vermuthlich der Regel nach so lange, als noch die Vitalitiat zur Production entwickelungsfähiger Eier ausreicbt. Es liegt anf der Hand, wie bedeutungsvoll eine solche im einzclnen Falle sich ergebende Sonderung der Regel nach im selben Körper vereinigter Gesehlechter auch von allgemeinen Gesichtspunkten der phylogenetischen Entwickelung der Formen ist. Wissen wir auch nicht, auf welche Weise sich eine derartige ausnahmsweise Trennung herausbilden kann, so ist doch der thatsächliche Befund, welcher die Möglichkeit dazu enthüllt, unter allen Umständen in Betracht zu ziehen.

Ohne mich an dieser Stelle weiter in speculative Erörterungen einzulassen, so verlockend die Gelegenbeit dazu auch erscheinen müchte, will ich hier nur andeuten, wie die angeführte Thatsache mich ganz besonders in der Ueberzeugung bestärkt, dass die digenetische Entwickelung nur eine höchste Phase der Ausbilung einer geschlossenen Reihe von verschiedenen Arten der Keimbildung darstellt, welche von der einfachen Vermehrung durch Wachsthum über die natürlichen Grenzen zur ungeschlechtliehen, monogenetischen, digenetisch-zwittrigen und endlich digenetisch gesonderten ansteigt. Nach dieser Anschaung würde die Organisation der Bilharzia als eine vorzeitige Erreichung der böheren geschlechtlichen Differenzirung durch Spaltung des Individuums zu betrachten sein.

Die merkwürdige Erscheinung dieser auch im Tode häufig nicht aufgegebenen Copulation wurde von den Autoren bereits wiederholt zur Darstellung gebracht, so von Hrn. Leuckart auf Seite 617 seines Werkes über die Parasiten, von Hrn. Küchenmeister als Fig. 13 auf Taf. VIII am oben genannten Orte.

Gleichwohl schien es mir angezeigt, darauf zurückzukommen und eine grössere mit dem Zeichenapparat nach dem Präparat 
entworfene Abbildung (Fig. 1 der Taf. XI) zu geben, da die Dimensionen del früheren nicht ganz correct erscheinen, zumal hinsichtlich der relativen Grösse beider Geschlechter und einzelner Details der inneren Organisation, mit denen ich mich nicht einverstanden erklären kann.

Das der Abbildung zu Grunde liegende Präparat ist mir deshalb besonders interessant, weil die Copulation beider Thiere aufgegeben wurde bis auf eine ganz kurze Strecke, d. h. diejenige, wo sich mit grösster Wahrscheinlichkeit die Befruchtung vollzieht.

Die hier in copula abgebildeten Exemplare sind ungewöhnlich klein, da das Männchen nur etwa $4 \mathrm{~mm}$, das Weibchen $8 \mathrm{~mm}$ misst, obwohl sie ihrem Inhalt nach unzweifelhaft reife Thiere waren. Ein anderes als Fig. 2 derselben Tafel in natürlicher Grösse abgebildetes Weibchen, in gleicher Weise conservirt, zeigt die von Hrn. Leuckart angegebene Grösse von $16 \mathrm{~mm}$ (16 bis $19 \mathrm{~mm}$ L.), auch habe ich in meinem Material erheblich über $4 \mathrm{~mm}$ grosse Männchen, die nach demselben Autor 12-14 mm lang sein sollen.

Die Schwankungen der Körpergrösse sind also bedeutend, für die Reife aber nicht wesentlich, dagegen muss ich einen gewissen Werth darauf legen, dass das vordere Körperende des Weibchens den Canalis gynaekophorus des Männchens um ein beträchtlicheres Stück ïberragt, als gewöhnlich gezeichnet wird, weil diese Stellung auf den Process der Befruchtung von Einfluss sein dürfte. Wie im vorliegenden Falle wird wohl auch in anderen der Längenunterschied $\mathrm{der}$ in Copulation tretenden Thiere ein grösserer sein als $1 / 3$ zu Gunsten des Weibchens, vielmehr wird letzteres wenigstens nahezu doppelt so lang sein als das Männchen. Die genaue Messung der männlichen Exemplare wird recht erschwert durch ihre Neigung sich spiralig zu einer Art Klumpen aufzurollen, eine Haltung des Körpers, welche ron dem als Fig. 1 abgebildeten Thiere gliicklicher Weise nicht angenommen wurde.

Das Hinterleibsende des Weibchens hat den Canal anf langer Strecke verlassen und richtete sich im Präparat, herunterhängend, mit dem Vorderende ungefähr parallel, indem es seine Einlagerung nur an einer dem Bauchsaugnapf des Männchens benachbarten Strecke beibehielt, wo die Vereinigung also jedenfalls die innigste war. 
Schon die gewählte schwache Vergrösserung lässt erkennen, dass die Körperoberfläche des dicken Warmes mit kleinen Hervorragungen besetzt ist, welche in der hinteren Körperbälfte am deutlichsten sind, nach vorn zu niedriger werden und schliesslich auf dem etwas conisch verjüngten vordersten Körperabschnitt, der die Saugnäpfe trägt, gänzlich verschwinden. Der weibliche Körper erscheint in der Figur glatt, ist es indessen ebenfalls nicht, wie die stärkeren Vergrösserungen lehren. Ein Theil der inneren Organisation ist an diesem Weibchen durch die Körperwandung zu erkennen, da das Präparat mit Carmin gefürbt und mit Canadabalsam aufgehellt wurde; der männliche Körper blieb trotzdem zu undurchsichtig um das Innere beurtheilen zu können.

\section{Organisation des weiblichen Geschlechtes.}

Das Weibchen ist bisher am unvollständigsten erlsannt worden, und ich bildete daher als Fig. 2, 3 und 4 der Taf. XI noch ein anderes Exemplar der Vergleichung wegen ab, welches nicht mit Canadabalsam aufgehellt, sondern in Gummiglycerin eingeschlossen wurde. Dies Exemplar ist recht wohl erhalten und enthïllte mir trotz der geringeren Durchsichtigkeit wegen des abweichenden Einschlussmittels die innere Organisation ziemlich gut, wenn ich auch zur Sicherstellung des Erkannten die Durchschnitte nicht entbehren konnte.

Das makroskopische Bild täuscht ein kleines Rundwürmchen, eine Filaria oder Trichosomum vor, da der Durchmesser nur 0,07 bis $0,26 \mathrm{~mm}$ beträgt, doch erkennt man mit der Lupc, dass das vordere Körperende Saugnäpfe führt, wie solche einer richtigen Trematode zukommen. Diesen gegen den Mundsaugnapf zu etwas conisch verschmälerten Vorderkörper messe ich, den Banchsaugnapf abgerechnet, ähnlich wie Hr. Leuckart $(0,22 \mathrm{~mm})$, zu $0,24 \mathrm{~mm}, 0,35 \mathrm{~mm}$ oder $0,225 \mathrm{~mm}$. Den Bauchsaugnapf selbst ebenso, nämlich $0,08 \mathrm{~mm}$; auch die Dickendimensionen sind wesentlich die nämlichen.

Aus den angeführten Zahlen ergiebt sich, dass die weiblichen Vorderkörper auf den Abbildungen der copulirten Thiere bei Hrn. Küebenmeister sowohl wie bei Hrn. Leuckart nach den von ihnen selbst gegebenen Maassen zu lang gezeichnet sind; daraus folgt. dann weiter, dass die Entfernung des Bauchsaugnapfes 
(der übrigens in Kü chenmeister's Figur anf dem Rïcken des Thieres gezeichnet wurde) bei sonst gleichbleibenden Längenverhältnissen der aus dem Canal hervorragenden weiblichen Körperenden von dem Eingang des Canales eine grössere sein muss als angegeben. So bringt es auch meine Fig. 1 zur Anschauung.

Schon bei mässiger Vergrösserung erkennt man, dass die Körperoberfäche des Weibchens nicht überall glatt ist, sondern besonders in der hinteren Hälfte Rauhigkeiten zeigt, die man bei Anwendung stärkerer optischer Systeme als feine cylindrische Stacheln erkennt, welche der Oberfläche anhaften. Dieselben sind am Schwanzende besonders deutlich entwickelt und zahlreich, während sie nach vorn zu seltener werden, um etwa vor der Körpermitte nur noch undentlich zu erscheinen. Da die Stacheln auch an meinen Prïparaten vielfach unregelmässig zerstreut auftreten und nur an weniger exponirten Stellen dichter gefunden werden, ist wohl anzunehmen, dass sie vergänglicher Natur sind und leicht abfallen. Ich glanbe daher gern, dass friblere Untersucher thatsäcblich glatte Körperoberflüchen vor sich hatten, da die Conservirung des Materials nach ihren eigenen Angaben zu wünschen übrig liess.

Die Richtung der feinen Stacheln geht an wohl erhaltenen Stellen von hinten nach vorn, und ich bin daher auf die Vermuthung gekommen, dass dieselben die Function zu erfüllen haben, ein Hindurchgleiten des Weibchens durch den Canalis gynaekophorus zu verhindern und somit zur Verlängerung der Copulation beizntragen, wie sich bei manchen Säugethieren nach rückwärts gerichtete Stacheln der Eichel zu gleicher Function ausgebildet haben.

An dem in eine vordere stumpfe Spitze ausgezogenen, hinten etwas herzförmig ausgeschnittenen Mundsaugnapf beginnt der einfache Darmcanal mit einer Mundöffnung, die sich sofort zu einer pharyngealen Erweiterung entwickelt und einen beträchtlichen Durchmesser des schmalen Vorderkörpers einnimmt. In Fig. 1 erscheint an dem weiblichen Körperende dieser Pharynx besonders deutlich und erinnert in seiner Form an einen Pokal; der Durchschnitt bestätigt die Realität des Verhältnisses, worüber Fig. 7 der Taf. XII verglichen werden mag. Die Muskulatur ist sowohl am Mundsaugnapf als auch am Pharynx, noch mehr aber 
an den zunächst weiter abwärts folgenden Abschnitten des Darmes eine nur dürftige, das Caliber selbst ausserordentlich wechselnd und unregelmässig.

Nach kurzem Verlauf theilt sich dicht über dem Bauchsaugnapf der Darm plötzlich in zwei Schenkel, die nun die Seitentheile des dünnen Würmchens einnehmen, um dazwischen nur einen schmalen, den Genitalorganen zugewiesenen Raum frei zu lasson. Die Haustra des Darmes markiren sich in den Figuren, wo sie leer waren, als durchsichtigere Stellen, in anderen Fällen sind sie an dem Inhalt, geronnenem, bereits schwärzlich gewordenem Blut kenntlich.

Nachdem etwa der vierte Theil der ganzen Körperlänge von dem Darm durchmessen ist, vereinigen sich die beiden Darmschenkel, von links und rechts zusammentretend, wieder zu einem gemeinsamen Canal, der in wechselnder Weite, undeutlich spiralig gedreht bis gegen das Hinterleibsende zieht, wo er in einiger Entfernung von der Schwanzspitze blind endigt. Die Vereinigungsstelle der beiden Darmschenkel ist durch ihre Lage unmittelbar hinter dem Eierstock eine gegebene, die Lage des blinden Endes schwankt. Ich mass die Entfernung von der Schwanzspitze bei drei Individuen als 0,$28 ; 0,20 ; 0,12 \mathrm{~mm}$.

Der weibliche Apparat beginnt in einer Falte hinter dem Bauchsaugnapf mit einem engen muskulösen Schlauch (von 0,18 mm Länge und nur 0,03 mm Breite), der das Mündungsstüek der Eierlegscheide darstellt. Nach kurzem Verlanf erweitert sich der Canal zu einem ampullenartigen Raum ron cylindrischer Gestalt mit verdickten Wandungen und etwa gleicher Länge, wie der erste Absehnitt $(0,16$ bei $0,1 \mathrm{~mm})$.

Dieser Raum, den wir als Uterus bezeichnen wollen ( $u$ der Fig. 8 auf Taf. XII), verengt sich alsdann wiederum ganz plötzlich und erscheint wie eingeschnürt, so dass regelmässige Längsfalten nach Innen vorspringen, und das Lumen etwa auf den dritten Theil reducirt wird. Unmittelbar hinterher geht es wieder nahezu auf die vorige Weite zuriack, die Wand des Canales ist aber viel dünner, häutiger, durch vorherrschende Längsfasern streifig; dieser gewöhnlich auch als Uterus bezeichnete Abschnitt verdient wohl mehr den Namen Eileiter (Oviduct).

So verläuft der Eileiter zwischen den Darmschenkeln für eine 
erhebliche Strecke ziemlich gerade und geht dann auf etwa $0,6 \mathrm{~mm}$ Entfernung rom Bauchsaugnapf in ein Organ iiber, welches schon von Bilharz ${ }^{1}$ ) gesehen, aber nicht richtig erkannt, von den späteren Autoren meistens gänzlich unbeachtet gelassen wurde. Er nannte es „die Kapsel", ohne sich am angeführten Orte über die etwaige Bedeutung auszusprechen; ich selbst sehe darin die Schalendrüsenböble und glaube, dass die Untersuchung des mikroskopischen Baues die Richtigkeit dieser Bezeichnung ergiebt.

Das Organ stellt einen Hohlkörper von ungefähr birnförmiger Gestalt, 0,08 breit und 0,15 mm lang dar, der auf dem unten in ihn einmündenden Gange aufsitzt wie die Frucht auf ihrem Stiele. Die Gestalt und Raumverbältnisse gestatten gerade einem reifen Ei des Wurmes bequeme Lagerung darin, wie solches in Fig. 3 bei $\mathrm{gl}$ in dem Hoblraum kenntlich wird.

Das hier abgebildete Weibchen war nicht in Copulation, der Process der Eiablagerung scheint unterbrochen worden zu sein, $\mathrm{da}$ dies $\mathrm{Ei}$ in der Schalendrüse das einzig reife ist, welches sich feststellen liess, während das copulirte Weibchen in Fig. 1 eine ganze Reihe hintereinander aufruickender Eier von der Drüse durch den Eileiter bis zur Mündung am Bauchsaugnapf aufweist. Auch im Eileiter lagern die Eier einzeln und würden neben einander in dem Rohr kaum Platz haben. Da sie offenbar je nach der Reifung vorwärts befördert und nach aussen entleert werden, so weiss ich nicht, wodurch die Meinung von dem Anschwellen des Weibchens nach der Befruchtung, wie sie sich in den Autoren ausgedrückt findet, eigentlich entstanden ist. Ohne eine Ansammlung von Eiern im Innern des Weibchens wird die Anschwellung jedenfalls keine erhebliche sein können und müsste auch wesentlich oberhalb des münnlichen Canalis gynaekophorus lagern.

Unterbalb der Schalendrüse wird der auf engen Raum zusammengedrängte weibliche Apparat zu verwickelt, um an Präparaten in Aufsicht erkannt zu werden, sondern dazu sind Querschnitte, auf welche sogleich zurückzukommen sein wird, unbedingt nöthig.

1) Brief an v. Siebold. Abgedr. in Zeitschrift f. wissenschaftl. Zoologie Bd. IV. 
Man erkennt am unversehrten Thier an dieser Stelle nur gewundene Canäle, welche in etwa der halben Entfernung als der Bauchsaugnapf von der Schalendrüse entfernt liegen und zu einem dunkel durchschimmernden unregelmässig ovalen Organ mit gelappten Bändern hinführen, welches den unpaaren Eierstock (Ovarium) darstellt. Unmittelbar hinter diesem fliessen die Darmschenkel zusanmen und nicht im hinteren Theil des Körpers.

Sebr bald werden neben dem schwach gewundenen Darm körnig durchsehimmernde Organe sichtbar, welche dem Eingeweide durch den grössten Theil des Körpers folgen, indem sie allmählich mehr und mehr an Mächtigkeit zunehmen (vit. der Fig. $=O r$ gana vitellina). Man bat sie jedenfalls mit Recht als Dotterkammern angesprochen. Es frägt sich nur, ob hicr wie bei anderen Trematoden eine zugehörige Dotterblase vorhanden ist, von welcher in der Durchsicht jedenfalls nichts zu erkennen ist.

Da die Dotterorgane das Schwanzende nicht ganz erreichen, so ist lier der Körper wieder mehr transparent; man bemerkt das blinde Ende des Darmes, sowie auch den Hauptsammelraum des Excretionsapparates, ein Verhältniss, welches bisher sonderbarer Weise beim Weibchen nicht zu constatiren gelang, obgleich dies Organsystem sogar von auffallender Mächtigkeit ist (vergl. cl. Fig. 4) und am Schwanzende mit deutlichem Porus excretorius nü̈ndet.

\section{Lagerung der Organe in den Durchschnitten.}

Hatten die Untersuchungen am unversehrten Thier bei der Dünne und leidlichen Durchsichtigkeit des Körpers schon einige Uebersicht der Organisation enthiillt, so war doeh Manches noch dunkel geblieben, was nur das Studium aufeinander folgender Durchschnitte klarstellen konnte.

Die Schwierigkeiten, welchen man bei der Herstellung vollständiger Schnittserien bei diesem Wurm begegnet, beruhen einmal in der beträchtlichen Länge bei sehr geringer Dicke und dann in der Unmöglichkeit, am erhärteten Material die Biegungen des Leibes auszugleichen, um genau quer gerichtete Schnitte erlangen zu können. Die erstgenannte Schwierigkeit kann man sich verringern, wenn man die Strecken des Körpers aus der Schnittreihe aussehaltet, wo eine wesentliche Aenderung der Organisation nicht 
eintritt, d. h. den mittleren Theil des Körpers von der Vereinigung der Darmschenkel bis gegen das letate Fünftel etwa, wo das Darmende und die Veränderungen im Excretionssystem wieder wichtig werden. Die Biegungen habe ich rorher controlirt und die Schnittrichtung so gew ihlt, dass ich ihre Lage an den Organen ermitteln konnte. So stellt die bereits erwähnte Fig. 8, obwohl sie einer Folge rou möglichst quer gestellten Durchscbnitten entnommen ist, wegen einer Umbiegung des vorderen Körperendes einen Schrägschnitt dar, weleher die weiblichen Organe unterhalb des Bauchsaugnapfes fast parallel ibrer Längsaxe getroffen hat.

Bei der dürftigen Körperentwicklung beeinflussen die einlagernden Organe den Umriss des Querschnittes sebr erheblich, so dass er einen bemerkenswerthen Wechsel erkennen lïsst. Die durch Alkoholwirkung entstandenen Schrumpfungen der Leibeswand lassen sich bei eingehender Vergleichung der aufeinander folgenden Schnitte mit ziemlicher Sicherheit feststellen, und habe ich nach diesen Vergleichungen die beistehenden Durchschnittsbilder schematisch entworfen.

Ein Blick auf dieselben zeigt, dass dem makroskopischen Anschein entgegen auch das weibliche Individuum nicht den Körperbau eines Rundwurmes hat, sondern in ausgresprochenem Maasse bilateral entwickelt ist. Auf das quere Oval des Vorderkörpers (a) mit dem einfachen Darm folgt unterhalb des Bauchsaugnapfes eine auf der Bauchseite eingezogene Figur (b), welche im Centrum den regelmässigen Umriss des Uterus, daneben die Darmschenkel und Andeutungen der Excretionsgefässe enthält. Die Einziehung entspricht eine: Bauchfurche, die dem Canalis gynaekophorus des Männchens homolog zu setzen wäre.

Recht auffallend erscheint der Querschnitt in der Höhe der Schalendrüsenböhle (c), da bier die Einlagerung der Organe allein nicht beschuldigt werden kann, die abweichende Körperform veranlasst zu haben. Die Mitte wird durch die Schalendrüsenhöhle aufgetrieben, die Bauchfurche wieder verwischt, aber die Darmschenkel sind im Durchmesser stark reducirt und doch dehnt sich der Umriss beiderseits von denselben nicht unbeträchtlich aus; er erscheint nun als Viereck mit abgerundeten Eeken, an welchem die dem Riicken entsprechende Seite sogar länger ist als die des 
Bauches. In den abgerundeten Ecken lagern die Excretionsgefässe, bier scbon meist recht deutlich entwickelt; trotz der weiten nachgiebigen Canäle hat also die Alkoholschrumpfung die Vorspriinge nicht za verwischen vermocht, und glaube ich daher, sie als normale Eigenthümlichkeiten dieser Körpergegend ansprechen zu müssen.
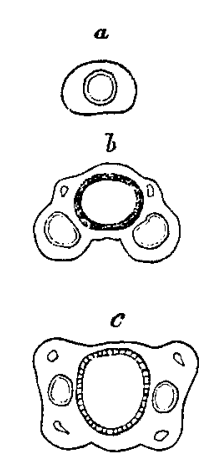

Ganz unähnlich den bereits beschriebenen gend des Eierstockes erreicht ist. Dies Organ wölbt die Rückengegend des Körpers stark hervor, während die mittelmässig weiten Schenkel des Darmes weiter ventral ihren Platz in den seitlich vorspringenden Wülsten finden. Es bleibt zwischen denselben ein medianes Feld frei, welches von dem Dottergang und dem Eileiter eingenommen wird, letzterer vom hinteren Ende des Eierstocks entspringend. Die Excretionsgefässe sind in dieser Region nur schwach entwickelt.

Erst jenseits des Eierstocks gewinnt der Körperquerschnitt eine mebr rundliche Gestalt (e), obwohl auch dann noch die beiden Hälften als Ausdruck der bilateralen Symmetrie in der Mitte verschmälert erscheinen, wie es beim Rundwurm

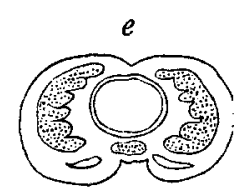
nicht der Fall ist. Die Darmschenkel haben sich unmittelbar hinter dem Ovarium vereinigt, so dass nun als Darm ein einziges grosses Lumen erscheint; daneben sehen wir rechts und links die rundlichen Läppchen der Dotterorgane, deren Ausfibrungsgang unterhalb des Darmes median seinen Platz findet. In diesem für den grössten Theil des Körpers wesentlich gleichbleibenden Umriss erscheinen neben dem medianen Dottergang die ziemlich weiten Hauptstämme des Excretionssystems.

Dem Ende schon ziemlich nahe verjingt sich der Durchmesser allmählich, während der Darm blind aufhört. Dicht unterhalb des Blindsackes treten die beiden Hauptstämme des Excretionsapparates in nahe Bertuhrung unter auffallend unregelmässig gestaltetem Lumen, welches in wechselnder Höhe and Ausdehnung an dem 
einen Gang cloakenartig erweitert ist. Das Bild ist bei verschiedenen Individuen so ungleich, dass ich darauf verzichtete, dies Verhältniss genauer zu erörtern und zur Darstellung zu bringen. Der Querschnitt zeigt bald eine, bald zwei oder drei durch deutliche Wandung abgegrenzte Lücken, aber kurz vor dem der Rückenlinie etwas genäherten Porus excretorius zeigt sich das Lumen wieder einfach, regelmässig begrenzt und ziemlich weit (f). Hier ist der verschmälerte Körper immer noch deutlich bilateral, die Bauchfurche breit und tief, die unterhalb des Eierstockes beginnende viel feinere Rückenfurche ist bis zum Körperende kenntlich ausgeprägt.

Die in den Durchschnitten kenntlichen histologischen Einzelheiten.

Die auf den beifolgenden Tafeln abgebildeten Durchschnitte sind alle bei derselben Vergrösserung (380) mittelst des Oberhäuser'schen Zeichenapparates entworfen, obne dass die zufälligen Unregelmässigkeiten corrigirt worden wären, um die objective Treae des Bildes nicht za trüben. Es wird dem Beschauer unter Vergleichung der schematischen Figuren nicht schwer fallen, sich die normale Form zu vergegenwärtigen.

Der feinere histologische Bau ist hier schwierig festzustellen, da die ungünstigen Verbältnisse des Körpers und die Beschränktheit des Materials gerade diese Species zu einem ungeeigneten Object für das Studium der histologischen Elemente machen. Unzweifelhaft ist Manches anders, zumal einfacher, als es sonst von besser entwickelten Formen beschrieben wurde, und dürfte es nicht wunderbar erscheinen, wenn eine so abweichende Species wie die Bilharzia auch im Aufbau der Gewebe manche Besonderheit zeigt.

Die Cuticula der Leibeswand erscheint als ein heller, stark lichtbrechender Saum von mässiger Breite, unter welchem das Körperparenchym mit den einlagernden muskulösen Elementen folgt, ohne dass sich eine subcuticulare Schicht deutlich davon unterscheiden liesse.

Auch die sonst beschriebenen Hautdrüsen der Trematoden waren in den Schnitten nirgends so deutlich, dass ich sie in den Abbildungen hätte eintragen können; bei sorgfältiger Durchmuste- 
rung sehr feiner Schnitte sieht man gelegentlich vereinzelte zellige Elemente, welche als Hautdrüsenzellen gedeutet werden können. Der Hautmuskelschlauch ist spärlich entwickelt und besteht hanptsächlich aus längsgerichteten Fasern, deren Durchschnitte cine Schicht rundlicher oder spindelförmiger Körperchen unter der Cuticula darstellen; wo ein Stlick der Leibeswand, wie z. B. bei Fig. 9 und 10 anf Taf. XII sich flach umgelegt hat, machen sich die Längsmuskeln als grobe Streifung bemerkbar.

Im Mundsaugnapf findet man die Muskelfasern stark verflochten, nicht eigentlich geschichtet, die radiär gestellten, gegen den stumpfen Apex desselben nach vorn aufstrebenden sind im Allgemeinen die stärksten.

Ringmuskeln sind als geschlossene Schicht nirgends kenntlich, obwohl vereinzelte, platte contractile Fasern zwischen der Cuticula und den Längsmuskeln vorkommen mögen, die aber von Bindegewebsfasern nicht sicher unterschieden werden konnten. Der Hautmuskelschlauch gewinnt gegen das hintere Körperende an Mächtigkeit, indem auch hier hauptsïchlich die Längsmuskeln verstärkt werden. Am Bauchsaugnapf sind wie gewöhnlich die radiären Muskeln, welche der Schrägsehnitt Fig. 8 meist quer getroffen hat, die reichlichsten; man erkennt aber am unteren Raude noch eine düne Lage der meridionalen Muskulatur. Die als Sphincteren wirkenden Kreisfasern konnten der Lage des Schnittes gemäss nicht wobl sichtbar werden; sie sind ebenso wie die Ringmuskeln der Leibeswand äusserst dürftig. Vereinzelte grosse Zellen von gangliösem Habitus, wie sie bei anderen Trematoden an dieser Stelle gefunden werden, gelangen auch zur Beobachtung.

Das Parenchym des Körpergewebes zeigt das von Bindegewebszellen gebildete Maschenwerk, welches an der Bitharzia bei dem geringen Gesammtdurchmesser des Körpers besonders grob erscheint. Die relativ grossen Kerne desselben gruppiren sich gern unregelmässig ohne ersichtlichen Grund, wie dies die Figuren 13 und 14, vom Schwanzende genommen, erkennen lassen. Wo grössere Organe einlagern, wird das Zwischengewebe spärlicher und erscheint ärmer an Kernen. Contractile Elemente, den dorsoventralen Muskeln anderer Trematoden entsprechend, sind jedenfalls zwischen gemischt, sie sind aber ebensowenig als die Ringmuskeln zum System geordnet.

Ausser den rundlichen, normal ausgebildeten Kernen finden 
sich hier und da etwa halb so grosse, mit Carmin imbibirbare, stärker lichtbrechende Körperchen im Gewebe.

Wie der Hautmuskelschlauch erst an der hinteren Körperhälfte einige Mächtigkeit gewinnt, so ist es auch der Fall an der Muskulatur des Darmkanals. Die pharyngeale Erweiterung ist von ciner scluwachen Wandung umzogen, an der Bindegewebe und Muskeln nicht wohl unterscheidbar sind. Das aufsitzende einschichtige Epithel ist erheblich niedriger als breit, die Zellen von klarem Inhalt mit abgeplatteten, blassen, vielfach undeutlichen Kernen.

Der Wandungscharakter des Darmes bleibt sich bis zur Verschmelzung der beiden Schenkel hinter dem Ovarium wesentlich gleich, nur dass die Dicke unterhalb der pharyngealen Erweiterung noch zarter erseheint. Das Epithel ist unregelmässig, indem sich zwisehen die niedrigen Zellen bier und da solche bis zur doppelten Höhe mischen (vergl. Fig. 9 und 10); der Zellinhalt erscheint nicht mehr so klar, aber noch fehlen protoplasmatische Auflagerungen anf denselben. Aufgenommenes Blut erfüllt das Lumen der beiden Darmschenkel als dunkeles, schwarzbraunes Coagulum in wechselnder Menge.

Nach der Vereiuigung der Schenkel gewinnt die Darmwand an Dicke unter Ausbildung muskulöser Ringfasern um die Tunica propria des Darmes. Das stärker entwickelte cubische, oder höchstens niedrig cylindrische Epithel trägt jene eigenthiimlichen Auflagerungen von körnigen Protoplasmafiddchen, wie sie von $\mathrm{Hrn}$. Sommer ${ }^{1}$ ) bei Distomum hepaticum beschrieben wurden. Dieselben verkleben zu Bündeln, so dass das eigentliche Lumen des Darmes einen unregelmüssig zackigen Umriss erhält (Fig. 12). Anbängende, von dem verdauten Inhalt herrührende Tröpfehen konnte ich nicht daran bemerken. Zuweilen heben sich die Auflagerungen von der Zellschicht als zusammenhängende Massen ab. Diesen Character behält der Darm bis gegen das blinde Ende bei, welches in Fig. 13 gerade in den Schnitt gefallen ist.

Die Histologie des Genitalapparates bietet den grössten Wechsel in der Erscheinung, wie er auch der am meisten

1) Die Anatomie des Leberegels Distomum hepaticum L. Arch. f. mikrosk. Anat. Bd. XXXIV, p. 576. 
complicirte ist. Das stark muskulöse Mündungsstück der Eierlegscheide hat durch diese Ausstattung besonders dicke Wandung, die auf dem Längsschnitt streifig erscheint mit kleinen, zwischen den Streifen eingestreuten länglichen Kernen. In der darauf folgenden ampullenartigen Erweiterung ist die. Wand kaum die Hälfte so stark, circuläre Fasern herrschen vor, doch bilden sie eine auf dem Durchschnitt fast bomogen erscheinende Masse.

Daran schliesst sich der häutige Eileiter, der an dem Uebergang in den Uterus durch die Wirkung der Ringmuskeln plötzlich auf ein kleines Lumen reducirt ist, unter Bildung von Längsfalten der contrahirten Wandnug; auf dies Verbältniss wurde bereits oben hingewiesen und gleichzeitig der hier auftretenden stirkeren Lïngsfasern gedacht, die von schwachen circulairen aussen bedeckt sind. In diesen Abschnitten der Eierlegscheide, Uterus und Eileiter kann ich ein deutliches Epithel nicht erkennen; ich lasse dahingestellt, ob es verloren gegangen, orler nur von so geringer Ausbildung ist, dass es auf den Schnittprïparaten sich nicht kenntlich von der Unterlage abhebt.

Dies ist um so anffallender als die weiter hinten liegende plïtzliche Erweiterung des Eileiters, die Schalendriisenhöhle, ein schr wohl entwickeltes Epithel von drüsigem Character fiuhrt. Die cubischen Epithelzellen wölben sich gegen das Lumen rundlich vor, fache Kuppen darstellend, die in Lüngsreihen im Organ angeordnet sind. Sie sitzen auf einer schwachen Basalmembran, welche die Tunica propria bildet; an der nach unten meist etwas excentrisch lagernden Einmïndungsstelle des Eileiters werden die Zellen höher und schmï̈ler, fast spindelförmig, indem sich die verschmälerten Enden in das darunter liegende Gewebe einsenken (Fig. 10). Dann erinnern sie am meisten an die gehïuften Zellen, wie sie bei anderen Trematoden die Schalendrüse bilden.

Die beiden Durchschnitte, die in Fig. 9 und 10 abgebildet wurden, sind auch dadurch interessant, dass ein zufällig in der Schalendrüse vorhandenes $\mathrm{Ei}$ sich dem Messer darbot und in seiner Lagerung erhalten blieb. Nachdem in einem höher gelegenen Schnitte der oberste Theil entfernt war, fiel der Hauptabschnitt in den Fig. 9 dargestellten, welcher lehrt, dass ein reifes Ei die Höble annähernd ausfüllt; in Fig. 10 erhielt sich davon der Seitenstachel, der in den etwas seitlich angefugten Gang des Oviductes hineinragt, dem Beschauer den Einblick in die Höhlung des 
Stachels gewährend. Bei Individuen, welche Eier mit Endstachel legen, verlängert sich der Oviduct gerade aufsteigend zur Schalendrüse; doch bemerke ich, dass mir kein Präparat zur Hand ist, wo ein solches Verbältniss stattfindet, ich mich aber berechtigt halte, aus dem vorliegenden Befund darauf zu schliessen, da sich hier die Eiform gleichsam vor unseren Augen gestaltet. Die Eier mit Endstachel sind übrigens jedenfalls sehr viel seltener, als die mit Seitenstachel, welche als das normale Vorkommen gelten können.

Unterhalb der Schalendrüse münden dicht benachbart die beiden häutigen Gänge ein, deren bereits oben gedacht wurde als um einander gewundener Canäle im medianen Gebiet des Körpers. Die Durchschnitte dieser Regionen zeigen vielfach Schrügschnitte und Schlingen der Gänge, aber stets links und rechts von den Darmschenkeln eingefasst. Die Wandung des einen Ganges erscheint etwas dicker, contractil, die des anderen nur bäutig; überall unterscheiden sich beide leicht und sicher durch den Inhalt, indem der erstere unreife, sein Lumen etwa ausfillende Eier führt (Fig. 11 od.), ler letztere stark lichtbrechende Körnchen, offenbar Dotterelemente (vi. derselben Figur).

Besonders instructiv wird der Durchsehnitt, wenn man den Gingen bis zur Höhe des Ovariums gefolgt ist, wie in dem Fig. 11 abgebildeten Schnitt geschehen. Dann streckt sich ihr Verlauf mehr gerade, sodass häufiger reine Querschnitte entstehen, während das Ovarium den mittleren Theil des Körpers stark gegen die Rückenseite hervorwölbt. Hr. Lenckart, der in diesem Gebiet nur von einem Gang spricht, dem Oviduct, hat das schwierig zu verfolgende Verhältniss desselben zum Ovarium, dass er nämlich das Ovarium in seiner ganzen Länge begleitet, um erst am hinteren Ende des langgestreckten Organs in letzteres zu münden, bereits richtig erkannt. Der Dottergang zieht sich aber noch weit über den Eierstock hinaus in das Schwanzende des Körpers.

Nach Analogie mit anderen Trematoden erwartet man in der Region, wo Oviduct und Dottergang sich mit der Schalendrüse verbinden, die Begattungsscheide, den La urer-Stieda'schen Canal, zu sehen, welcher zum Rücken verläuft, um dort zu münden. Wiederholte, sorgfältige Durchmusterung der Präparate konnte mir 
ein klares Bild von ihm nicht verschaffen, gleichwohl halte ich mich von seiner Existenz iiberzeugt.

Der Grund dafür liegt fül mich hauptsächlich in der Art der Copulation, insofern das Weibchen, wie Fig. 1 es zeigt, dem mit Begattungswerkzeugen nicht ausgestatteten männlichen Geschlcchtsapparat so angepasst wird, dass die Genitaliofnung der Stelle, wo man die Begattungsscheide vermuthen sollte, gerade anliegt. Olme einen Porus, welcher den Uebertritt des Samens ermöglichte, kionnte derselbe unter den gegebenen Verbiiltnissen kaum zu den reifenden Eiern gelangen. Man müsste denn annchmen, dass er, aus der männlichen Oeffnung austretend, lïngs der Bauchfurche des Weibchens bis zur Mündung des weiblichen Apparates am Bauchsaugnapf aufstiege, um nun im Innern den vorrickenclen Eiern entgegen, denselben Weg nochmals zurück zu legen, was äusserst unwahrscheinlich ist.

Ich glaube auch die Mündung der Begattungsscheide gesehen zu haben, doch nicht deutlich genug, uu bei der Kleinheit des Objectes die Möglichkeit eines künstlichen Defectes im Präjarat ausschliessen zu können. Als ich die erste kume Beschreibung: dieser Verbältnisse veröffentlichte ${ }^{1}$ ), war mir das reihenweise Aufriicken der reifen Eier in der Eierlegscheide noch unbekannt und ich glambte die Möglichkeit einer Befruchtung durch Anfsilugung des Sameus, der sich in den Bauchkanal des Weibehens bei der andauernden Copulation ergossen hätte, durch die Mündung nnterhalb des Baugsaugnapfes anfrecht halten zu müssen, wofiir ich aus den angeführten Griuden nun nicht mehr eintreten möchte. Beiliiufig bemerkt, ist selbst bei dem krïftig entwickelten Distomum hcpaticum die Begattungsscheide im contrahirten Zustande ron auffallender Feinheit, so dass ihr verspätetes Bekanntwerden nicht Wunder nehmen kann.

Das am mächtigsten ausgebildete Organ des weiblichen Körpers ist das Ovarium, von dem man behaupten darf, dass es in seinem Bau von demjenigen anderer Trematoden in ähnlicher Weise abweicht, wie es in ihrer Weise die Schalendrüse thut. Es stellt eine sackartige Bildung dar mit solider Wandung, die das Keimepithel im Innern trägt. Die rapide Vermehrung und steigende

1) Zur Anatomie der Bilharzia haematobia Cobbold. Zoologischer Anzeiger Nr. 199, 1885. 
Entwickelung der Eizellen erfült den Binnenraum mit zelligen Elementen verschiedener Grösse, die sich aneinander drängen und gegenseitig abplatten.

Auch feinkörnige Massen bemerkt man in wechselnder Ansammlung um die reiferen Eizellen, welche man wohl als Eiweiss ansprechen muss; an welcher Stelle des ganzen Systems dasselbe abgesondert wird, vermochte ich nicht zu entscheiden.

Die Grösse der reifenden Eizellen im Ovarium schwankt in weiten Grenzen, nämlich etwa von 0,005 bis $0,13 \mathrm{~mm}$.

Ist der Querschnitt des weiblichen Körpers in der Gegend des Ovariums besonders complicirt, so wird er dafür jenseits desselben nach dem Schwanzende zu plötzlich wieder ausserordentlich einfach. Dies geschieht sowohl durch die beschriebene Verschmelzung der beiden Darmsehenkel zu einem einzigen Canal, als auch durch die Vereinfachung des Genitalsystems, von dem nur die Dotterorgane dem ganzen hinteren Abschnitt des Körpers zugewiesen sind. Auch der Dottergang, weleher seinen Platz unter dem Darmkanal findet, ist hier nur noch von sehr dünnen Wandungen umgeben, so dass er allmählich undeutlich wird.

Die Hauptmasse des ovalen, in zwei seitliche Hälften symmetrisch eingetheilten hintereu Körperabschnittes stellen die Dotterkammern mit ihrem Inhalt dar, welcher in keinem wesentlichen Punkte von demjenigen der besser bekannten Trematoden abweicht. Es sind rundliche oder unregelnäissig polygonale Zellen von etwa 0,01 Grösse mit deutlichem, kräftig tingirbarem Kern, die bei fortschreitender Umbildung zu Dotterelementen zerfallen, anfangs noch gruppenweise zusammenliegend, später, in den Ausführungsgängen als locker gehäufte Dotterkörnchen oder Schüppchen.

Histologische Elemente des Excretionsapparates sind wenig kenntlich. Hier und da sieht man die Gefässlücken von endotheloiden Schüppchen bekleidet und gewinnt in dem Endtheil, wo die Gefässe kloakenartige Erweiterungen tragen, die Vorstellung, dass hier im Leben ein Wimperbesatz auf niedrigen Zellen vorhanden ist, der aber vielleicht nicht den ganzen Innenraum gleichmässig bedeckt. Da auch die beste Alkoholconservirung Form und Anordnung so zarter Elemente nur unvollkommen vor Augen fïhrt, so unterlasse ich es darüber genauere Angaben za machen.

Die coagulirten Massen, welche hier nicht selten im Lumen 
der Quersehnitte erscheinen, sind sehr feinkörnig, bilden unregelmässige lockere Haufen und werden durch Carmin blassroth tingirt.

In den vorstehenden Zeilen geschah nirgends Erwähnung des Centralnervensystems, und zwar aus gutem Grunde. Zum Studium dieses bei den Wïrmern besonders schwierig za behandelnden Organsystems würde man sich gewiss nicht gern eine Species wie die vorliegende auswiihlen, um Einsicht in den Aufbau desselben zu gewinnen. Man ist zufrieden, wenn man am Pharynx die dïrttigen Zellanhäufungen findet, welehe den pharyngealen Ganglien entsprechen, und hier und da von ihnen ausgehende Fiddchen beobachtet; irgend welche Besonderheiten würde ich nicht wagren nach den vorliegenden Präparaten aufmustellen. Ich betone nur noch, dass ich hier, wie bei anderen 'Trematoden gencigt bin, die multipolaren Zellen mit bläschenförmigem Kern, welehe sich zwischen den Muskelbiindeln eingestreut finden, als gangliöser Natur anzusprechen.

\section{Organisation des männlichen Geschlechtes.}

Der anatomische Bau des so krüftign entwickelten männlichen Geschlechtes ist ausserordentlieh einfach. Die hier sebr vicl leichtere Untersucbung erlaubt es mit Sicherheit Angaben zu machen, welche beim Weibchen nur unter einem gewissen Vorbchalt gegeben werden konnten; der Natur der Sache nach fallen diese Angaben vielfach negativ aus.

Die auch bei der männlichen Bitharzia wie bei den meisten Trematoden vorhandene platte Körperform wird, wie oben erwähnt, durch die Einrollung der Leibeswand um das auf der Bauchseite sich einfitgende Weibchen zu einer ruodlichen, die auch erhalten bleibt, wenn die Individuen die Copulation aufgegeben haben. Die Einrollung beginnt dicht hinter dem Bauchsaugnapf und verläuft bis zum stumpf abgerundeten Körperende. In der von Hrn. Le u ckart') gegebenen Abbildung der vorderen

1) a. a. O. p. 621, Fig. 211. In dieser Figur ist einer der rundlichen Körper, welche die Hoden darstellen sollen, rundlicher und heller als die übrigen gezeichnet. Ich möchte glauben, dass dieser die Samenblase ausdrückte. Von der im Text beschriebenen Ausmündung des männlichen Genitalapparates ${ }_{n}$ dicht hinter dem stark abgeschnürten Bauchsaugnapf“ zeigt 
Körperhälfte eines Männchens müssen die sich hinter dem Bauchsaugnapf kreuzenden Linien, welche sonst unverständlich wären, auf die sich iibereinander legenden Ränder der Leibeswand bezogen werden. Diese nämliche Figur zeigt auch rundliche Körper von etwas unregelmässig birnförmiger Gestalt als die Hoden des Thieres, eine Darstellung, die geeignet ist, wegen der feblenden Beziehung unter einander und dem Mangel der äusseren Begattungsorgane den Eindruck des Unvollständigen zu machen, und doch ist thatsächlieh in Wirklicbkeit nicht viel mebr vorhanden, als diese Abbildung zeigt.

Der Eindruck eines Rundwurmes wird beim münnlichen Geschlecht noch verstïrkt durch die Neigung des Körpers hinter dem Bauchsaugnapf sich aufzurollen in engen Windungen, wie es etwa die männliche Spiroptera thut. So bildet das 'Thier im Blute einen kleinen Klumpen von hellerer, weisslicher Farbe, wenn der Darmcanal wenig gefiullt ist, oder von schwïrzlicher, wenn der Wurm sich wie gewölınlich stark mit Blut vollgesogen hat. Die äussere Oberfliche erscheint auch bei diesem Geschlecht dem unbewaffneten Auge glatt, das Mikroskop dagegen lehrt, dass die äussere Oberfläche, die Rückenseite des Thieres dicht mit papillenartigen Erlebungen besetzt sind, welche niedrig in der Region des Bauchsaugnapfes beginnen, um dann, allmählich höher werdend, bis gegen das Sehwanzende zu verlaufen (vergl. Fig. 1 anf Taf. XI und Fig. 5 auf Taf. XI). Die papillijsen Erhebungen sind mit kleinen, cylindrischen Stacheln dicht besetzt, welche denen des weiblichen Körpers ähnlich sehen, nur dass letztere feiner sind und nicht auf Erhebungen gruppirt erscheinen. Auf der zum Canalis gynaeliophorus eingerollten Bauchseite des männlichen Körpers feblen die Papillen sowie die Stacheln; nur gegen das Schwanzende zn wird die Oberfläche des im Uebrigen glatten Canals wieder rauher (Fig. 6). Auch der vordere conische Theil des Körpers vom Mundsaugnapf bis zum Bauchsaugnapf trägt nur niedrige, stumpfe Rauhigkeiten.

Die Saugnäpfe sind sehr viel kräftiger als die des Weibchens

die Figur keine Andeutung, ebenso wenig von dem fast gerade zu ihr aufsteigenden Gang, der sich durch eine gewisse Dicke seiner Wandungen auszeichnen soll. Meine Querschnitte dieser Körperregion zeigen auch Nichts von einem solchen Gange. 
entwickelt, entsprechen ihnen aber in der allgemeinen Form; auch bier steigt der Mundsaugnapf zu einer stumpfen Spitze anf (Breite 0,2; Höhe 0,26), während sich im hinteren Theil auf ciner brïckenartigen Erhebung in der Höhlung desselben die Mündung des Schlundes befindet (Fig. 1, o.).

Eine pharyngeale Erweiterung ist hier nur sehr schwach ausgeprägt, dagegen markirt sich die Pharynxregion durch kräftigeren Muskelbelag mehr als beim Weibclien. Das enge Darmlumen spaltet sich oberhalb des nur etwa 0,22 Abstand von der Mundoffnung zeigenden Bauchsaugnapfes wie gewöhnlich in zwei Schenkel, welche nach rechts und links um letzteren hermmziehen.

Die Lumina dieser beiden Darmschenkel sind beim Männchen keineswegs so ansgedehnt wie beim Weibchen, wo sic hinter dem Bauchsaug'napf den grössten 'Theil des Körperinhaltes beanspruchen; die engen, leicht geschlängelten Darmschenkel messen in der Höhe der Genitalorgane bei dem als Fig. 5 abgebildeten Durchschnitt beispielsweise durchschnittlich nur 0,029 und nehmen so lediglich den zehnten Theil des ganzen Querdurchmessers ein. Die geringe Entwickelung des männlichen Darmkanals ist wohl der Grund, dass derselbe bisher nicht mit Sicherheit verfolgt wurle. Zu den mancherlei Räthseln, welche die Bilharaia dem Zoologen darbietet, würde noch ein weiteres hinzukommen, wenn auch die Anordnung des Darmkanals bei beiden Gesehlechtern in wesentlichen Punkten auseinander ginge. Dies wäre der Fall, wenn die beiden Schenkel bei dem einen, dem Weibehen, wieller verschmelzen würden, bei dem andern aber, dem Mainncben, die Verschmelzung ausbliebe. Eine solche Versehiedenheit existirt aher thatsächlich nicht, da beim Männehen wie beim Weibchen nahe hinter der Keimdrisse die Verschmelzung der beiden Schenkel erfolgt. Fig. 6 auf Taf. XI zeigt einen Körperdurehschnitt aus dem Schwanzende des Männchens mit dem Lumen des daselbst einheitlichen Darmcanals, der auch hier im Verbültniss zur Masse des Parenchyms dürftig entwickelt erseheint ${ }^{1}$ ).

Das blinde Ende des Darmes findet sich nahe am Schwanze in etwa $0,34 \mathrm{~mm}$ Abstand von der stumpfen Spitze.

1) Hr. Küchenmeister spricht überhaupt nur von einer Annäherung der Darmschenkel fast bis zur Vereinigung, was thatsächlich unrichtig ist. 1. c. p. 311 . 
Hierin liegt also ein Differenzpunkt meiner Darstellung gegenüber der von Hrn. Leuekart gegebenen, den za erklären ich etwas weiter unten versuchen möchte.

Es reiht sich daran ein zweiter, den ich seiner allgeneinen Wichtigkeit wegen niclst unterdriicken kann, nämlich die Lage der männlichen Geschlechtsöff numg, wenigstens ist die darüber gemachte Angabe genauer zu formuliren.

In Hrn. Leuckart's ${ }^{1}$ ) Diagnose heisst es: „Geschlechtsöfinung in beiden Geschlechtern hinter dem Bauchsaugnapf." Wir haben gesehen, dass beim Weibchen die Eierlegscheide thatsächlich unmittelbar am und hinter dem Bauchsaugnapf mïndet, wir wïrden aber beim Männchen an der cntsprechenden Stelle vergeblich nach einer Oeffnung des Geschlechtsapparates suchen. Da Hr. Leuckart selbst von einem kurzen, muskulösen Samenleiter spricht, die Hoden aber in betrïchticher Entfernung vom Bauchsaugnapf zeichnet, so ist die Angabe wohl nicht so scharf aufzufassen, wie sie ausgedrückt wurde.

Nach meinen Frfahrungen liegen die Hoden allerdings nur in einem sehr mässigen Abstand vom Banchsauguapf, also wird die Mïndung trotz des nur kurken Ausfibrungsganges anch nicht weit hinter dem bezeichneten Organ licgen können, aber sie ist thatsächlich durchans anders placirt wie die Mündung der Eierlegscheide, was mir für die Function wichtig erscheint.

Die Mündung des Samenleiters liegt nämlich nicht exponirt an Rande des Saugnaptes, sondern in der Tiefe des Anfangsstuickes vom Canalis gynaeliophorus verborgen.

Da dem Thier männliche Copulationsorgane fehlen, so wïrde eine freie Ausmiindung des Samenganges der Befruchtung weniger günstig sein, während bei Erguss des Samens in den vom Weibchen eingenommenen Canal, welches der Oeffnung gerade mit den Körpertheil anlagert, wo die Begattungsscheide zu vermuthen ist, selbst obne Begattungsorgane der Uebertritt in den weiblichen Körper durch Aufsaugung ungemein leicht vermittelt werden könnte.

Nach genauer Durchmusterung vollständiger Schnittserien glaube ich das thatsächliche Fehlen wirklicher Begattungsorgane,

1) a. a. 0. S. 617 . 
was noch immer als offene Frage behandelt wurde, nunmehr mit positiver Gewissheit behaupten za können.

Wie die weibliche Kcimdriise eine sackförmige Beschaffenheit angenommen hat, so ist es auch mit der miznnlichen der Fall. Das Organ zerfallt in eine Anzahl beutelförmiger Theile, deren bis acht vorhanden sein sollen. In einem von mir genauer untersuchten Falle betrug die Zahl der Hodenblasen fünf, wie es auch von Bilbarz ursprünglich angegeben wurde.

Dieselben bilden eine ziemlich dicht gedrängte Gruppe in der Körperregion, wo die Seitenränder sich beginnen einzurollen, und bängen untereinander durch die häutigen Austiilurungsgäinge von erheblicher Weite (v. d. der Fig. 5) zusammen. Wo die Oberfläche der Leibeswand von dem gemeinsamen Gang beinahe erreicht ist, fügt sich linkerseits, wie einc Ausstïlpung, ein anderer rundlicher Raum an, der den Hodenblasen an Grösse ungeführ gleich ist (Querdurehmesser des Hoden $=0.08$, Samenblase $=0.06$ ). Dieser Raum, den ich als Samenblase anspreche (v.s. der Fig. 5), unterseheidet sich sowohl durch den Bau seiner Wandung als durch seinen Inhalt von den wirklichen Hodenblasen, mag aber gelegentlich wohl diesen beigerechnet worden sein.

Mit dieser auf's knappste Maass beschränkten Organisation des Geschleclitsapparates ist die von mir $z \mathfrak{u}$ gebende Darstellungr erschöpft und glaube ich nicht, dass spätere Untersucher wesentliche neue, bisher von den Autoren etwa iibersehene Theile desselben finden werden.

Der Excretionsapparat ist dem des Weibchens ähnlich, doch ist auch hier der Durchmesser der Hauptstämme wie heim Darmcanal relativ geringer. Zwei Längsstämme sind vorherrschend, welche gewöhnlich sehr ungleiches Caliber zeigen. Ist der eine sehr überwiegend, so imponirt er im Querschnitt ähnlich wie der Durchschnitt eines Darmschenkels, wenn ihm anch selbstverständlich das dem Darme eigene Epithel fehlt. Ist die Conservirung des Epithels misslungen, so mangelt auch diese Unterscheidung, und dann bleibt eine Verwechselung sehr möglich. Ich hege desshalb die Vermuthung, dass da, wo zwei Darmschenkel im hinteren Körperabsehnitt der Bilharzia dargestellt wurden, das eine Excretionsgefäss als zweiter Darmschenkel verzeichnet worden ist.

Seitliche Aeste der Hauptstämme sind noch hier und da für ganz kurze Strecken im Parenchym kenntlich, verschmelzen aber 
sehr bald mit den Parenchymsticken in so hohem Maasse, dass eine weitere Verfolgung ausgeschlossen bleibt. In der Nähe des Schwanzendes fliessen die beiden ungleichen Hauptstämme and ein mittlerer, nur schwach entwickclter zu einer kurzen Cloake zusammen, welche schliesslich als enger Porus excretorius mündet.

\section{Histologische Elemente des männlichen Körpers.}

Wie schon aus der soeben gregebenen Darstellung der Organisation erhellt, beruht der grössere Umfangr des männlichen Körpers nicht sowohl auf einer mächtigeren Ausbildung der in ihm entbaltenen Organe, sondern die Leibeswand und das Parenchym selbst nehmen bei Weitem den grössten Raum desselben ein.

Die starke Cuticula der Oberfläche ist zu den bereits angefuihrten, warzenförmigen Erhebungen mit den feinen Stacheln entwickelt; auch hier folgt unter der Cuticula eine wesentlich liings gerichtete, zum Theil recht starke Muskulatur, deren Fasern in parallel geordnete Bündel vereinigt sind. Fig. 5 zeigt diese Muskelstreifen im unteren Theil der Figur ziemlich genau quer durchschnitten, während in der Mittellinie des Rückens sich die Elemente etwas schräg zum Messer gestellt haben. An der zum $\mathrm{Ca}$ nalis gynaekophorus einsinkenden Bauchseite sind diese Muskelbänder nur schwach entwickelt, dagegen fängt sich ein hauptsächlich quer angeordnetes System an geltend zu machen.

Dies beginnt, wie es die Figur zeigt, jederseits als dichte zusammenschliessende Gruppen dorso-ventraler Muskeln, welche bei völlig ausgebildetem Canal (vergl. Fig. 6) von beiden Seiten zusammenfliessend ilun von links nach rechts umspannen und so zur Fixirung des in dem Raum aufgenommenen Weibchens beitragen werden. Abgesehen von diesen Muskelsystemen sind die contractilen Fasern im Gewebe auch hier nur unregelmässig und spärlich vertheilt; circuläre Fasern der Leibeswand, die dem Rücken des Körpers angebören sollten, kann ich hier so wenig finden wie beim Weibchen. Die Muskulatur des 0,26 mm im Durchmesser haltenden Bauchsaugnapfes bot mir nichts Besonderes dar.

Hautdrüsen scheinen mir, auch bei der männlichen Bilharzia nur kiümmerlich ausgebildet zu sein. Die Hauptmasse des Parenchyms sind die sternförmig verzweigten Bindegewebszellen mit den rundlichen, etwa $0,006 \mathrm{~mm}$ grossen Kernen, welche stellenweise 
stärker angehäuft erscheinen. Gewebslücken und Excretionsgefässe sind im vorderen Theil des Körpers nicht wohl zu unterscheiden.

Auf den engen und kurzen, muskulösen Plarynx folgen die duinnwandigen Darmschenkel, deren Epitbel alsbald hinter dem Banchsaugnapf an Höhe gewinnt und den eigenthiimlichen Besatz von Protoplasmafialchen bekommit, wie ihm das Weilohen erst in erheblichem Abstande vom Bauchsaugnapf aufiveist. Die Darmwandung selbst ist im Querschnitt schmal, Muskeln daran wonig ausgeprägt.

In den Hodenblasen finden sich rundliche Massen, welche nach Analogie mit den Beobachtungen an höheren Thieren wohl als zusammengeflossene samenbildende Elemente aufzufissen sind, wie solche bei nicht ganz energischer Conservirung leicht entstehen. Normaler Weise bekleidet jedenfalls anch hier wie beim Ovarium das keimbildende Epithel die Innenflïche der Blase and drängt die reifenden Elemente nach dem Lumen vor, von wo sie durch die vis a tergo oder die Contraction der dorso-ventralen Muskeln weiter greschoben und in den gemeinsimen Gang ged rängt werden. Die Wand der Hodenblasen selbst mïchte ich als nicht contractil ansprechen, dagegen ist die Wand der seitlich angefiignten Samenblase ( $\mathrm{s}$ der Fig. 5) muskulöser Natur und wwar besonders im hinteren, weiteren Theil.

Die Innenfliiche der Samenblase zeigt kein deatliches Epithel (ebenso wenig wie solches an der Vagina und Uterus des Weibchens zu finden war), wohl aber eine höchst sonderbare cuticulare Bekleidung der Oberfliche, welche wie aus stark lichtbrechenden gewölbten Plïttchen von geringer Grösse zusammenǧefüggt erscheint. Die Glätte und Regelmässigkeit dieser Oberflächenstruetur schliesst die Möglichkeit aus, dass etwa angebackene Elemente des Inhaltes die Erscheinung hervorrufen könnten.

Als wirklicher Inhalt des Raumes fanden sich in den abgebildeten Präparat zwar coagulirte, aber noch erkennbare Samenkörperchen vor, theilweise umbüllt von einem blassen Gerinnsel. Die rundlichen, körnig-zelligen Massen der Hodenblasen fehlten hier durchaus.

In den Hauptstämmen der Excretionsgefässe waren gegen das Schwanzende zu die Endothelauskleidungen deutlicher als sie beim Weibchen beobachtet wurden, auch hier fanden sich feinkörnige blasse Gerinnsel gelegentlich im Lumen vor (vergl. Fig. 6). 
Das Centralnervensystem ist schon kenntlicher wie beim weiblichen Geschlecht durch die gangliösen Zellgruppen hinter dem Mundsaugnapf als pharyngeale Ganglien ausgeprägt, Besonderheiten desselben habe ich nicht zu constatiren.

Auch in Betreff der Eier, der in ihnen sich entwickelnden Embryonen, sowie uiber das Sehicksal der ausgeschliiptten Embryonen, diese besonders wichtige Frage habe ich nichts Neues zu verzeichnen, sondern verweise anf die gerade hierin ausfïhrlichen Arbeiten ron Sonzino, Kartulis, Cobbold und Anderen.

\section{Litteratur.}

Leuckart, Die menschlichen Parasiten.

Bilharz, 1. Distonum hacmatobium und sein Verhältniss zu gewissen pathologischen Veränderungen der menschlichen Harnorgane. Wiener med. Wochenbl. Nr. 4 u. 5, 1k5ij. 2. Bricf von B. an Siebold. Zeitschr. f. wissenschaftl. Zoolog. Bd. IV.

Kiichenmeister, Die thierischen Parasiten des Mensehen. Theil I. p. 340 .

Cobbold, 1. Parasites of Man. 2. On the devellopment of Billharzia hacmatobia together with remarks on the ova of another Urinary Parasite o ccuring in a case of Hacmaturia from Natal. British Med. Journ. 1872.

Harley, On the endemic Haematuria of the Cape of good hope. Medico-chirurg. Transactions. Vol. XLVII, 1864, p. 52-72.

Sonzino, 1. Della Bilharzia haematobia e delle alterazioni anatomopathologiche, che induce nell' organismo umano etc. Pubblicata nel giornale medicale l'Imparziale di Firenze 1885. 2. Ricerche sullo sviluppo della Bilharzia haematobia. Fstratto dal giornale della R. Accademia di medicina di Torino, agosto 1884 .

Kartulis, Ueber das Vorkommen der Eier des Distomum haematobium Bilharz in den Unterleibsorganen. Arch. f. patholog. Anat. u. Physiol. Herausgeg. v. Virchow. Bd. 99, p. 139. 


\section{Erklärung der Abbildungen auf Tafel XI und XII.}

Bezeichnungen, welche bei allen Figuren in gleicher Weise zu deuten sind:

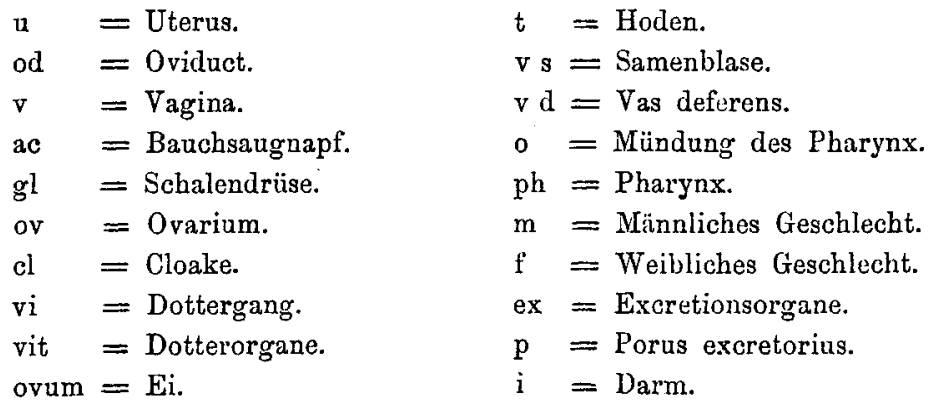

Fig. 1. Zwei Individuen in Copulation. Im Eileiter des Weibchens etwa 12 reife Eier, die in einer Reihe hinter einander angeordnet sind. Der Vorderkörper mit dem Bauchsaugnapf des Weibchens erscheint in Aufsicht. Vergr. 28.

Fig. 2. Weibliches ausgewachsenes Individuum in natürlicher Grösse. Vom Präparat durch aufgelegtes Pauspapier abgezeichnet.

Fig. 3. Dasselbe Exemplar, vordere Kï̈rperhälfte; der Bauchsaugnapf von der Seite gesehen. In der Schalendrüse ein reifes Ei. Vergr. 28.

Fig. 4. Dasselbe Exemplar, hintere Körperhälfte. Vergr. 28.

Fig. 5. Querschnitt eines männlichen Individuum's durch die Geschlechtsorgane am Beginn des Canalis gynaekophorus. Die Leibeswand des Rückens hat sich im Schnitt etwas schräg gestellt. In der Samenblase coagulirte Samenelemente. Hartnack V. Vergr. 380.

Fig. 6. Querschnitt desselben Männchens, aus der hinteren Hälfte des Körpers. Der Darm ist wieder einfach. Links und rechts davon die zwei Hauptstämme des Excretionsapparates. Ha rtna ck V. Vergr. 380.

Fig. 7. Querschnitt durch den Vorderkörper des Weibchens dicht hinter dem Mundsaugnapf, welcher die pharyngeale Erweiterung des Tractus zeigt. Hartnack V. Vergr. 380 .

Fig. 8. Schnitt der vorderen Körperhälfte desselben Individuum's dicht hinter dem Bauchsaugnapf. Wegen zufälliger Krümmung des Körpers ist der Schnitt hier nahezu in die Längsaxe gefallen. Er zeigt die Endigung des weiblichen Geschlechtsapparates hinter dem Bauchsaugnapf. Hartnack V. Vergr. 380.

Fig. 9. Querschnitt desselben Individuum's durch die Mitte der Schalendrüse. In der Höhlung ein ebenfalls quer durchschnittenes Ki. Hartnack V. Vergr. 380.

Fig. 10. Querschnitt desselben Individuum's durch das hintere Ende der Schalendrüse. In der etwas seitlich angefügten Fortsetzung des 
Eierganges liegt noch der abgeschnittene Seitenstachel des Eies, in dessen Hohlraum man hineinblickt. Hartnack V. Vergr. 380.

Fig. 11. Querschnitt desselben Individuum's durch die Mitte des Ovarium's. Zwischen dem Ovarium und den Darmschenkeln erscheint die Leibeswand etwas eingesunken. Hartnack V. Vergr. 380.

Fig. 12. Querschnitt durch den dicksten Körpertheil desselben Individuum's. Der einfache Darm ist dicht umbüllt von den Dotterorganen, deren Ausführungsgang die Mitte der Bauchseite einnimmt. Harta a ck V. Vergr. 380 .

Fig. 13. Querschnitt desselben Individuums in der Höhe des blinden Darmendes. Neben dieser Kappe der Darmwand eine unregelmässige Erweiterung des Excretionsapparates nach Art einer Cloake. Die feinen Stacheln der Leibeswand sind auf der Bauchflïche ziemlich vollständig erhalten. Elartnack V. Vergr. 380.

Fig. 14. Querschnitt desselben Individuum's kurz vor der Ausmündung des Excretionsapparates als Porus excretorius. Ein Rest der Darmwand ist noch in den Schnitt gefallen. Hartnack V. Vergr. 380.

Sämmtliçhe Figuren mit Ausnahme von Fig. 2 sind mit dem 0 berhäuser'schen Zeichenapparat entworfen.

\section{Zur Kenntniss der Spinalganglienzellen beim Säugethier.}

Von

Hans Daae, stud. med. aus Norwegen.

(Aus dem anatomischen Institut in Kiel.)

Hierzu Tafel XIII und XIY.

Bei den vielen Untersuchungen, die im Laufe der letzten 50 Jahre über die Spinalganglien angestellt sind, hat es sich besonders um die Frage nach der Zahl und dem Verhalten der Ganglienzellenansläufer gehandelt, sowie um die weitere Frage, ob hierin Uebereinstimmung bei sämmtlichen Wirbelthieren herrscht. Die frühesten dieser Arbeiten wurden von R. Wagner ${ }^{1}$ ) an Fischen

1) R. Wagner, Neue Untersuchungen über den Bau und die Endi- 